\title{
Hepatotoxicidad por productos de herboristería
}

\section{MEDICINA NATURAL}

En las últimas décadas estamos viviendo un incremento de la popularidad de la medicina natural y del consumo de productos botánicos en los países desarrollados. Este aumento es debido principalmente a la percepción de que al ser "naturales" solo pueden ser beneficiosos y no presentan riesgos para la salud. Sin embargo, al igual que los medicamentos sintéticos, no carecen de posibles efectos adversos. Los factores que pueden contribuir a la toxicidad de los productos de herboristería son el efecto tóxico de la/s sustancia/s del mismo, la falta de identificación del producto y de sus componentes, la selección de una parte errónea de la planta, el almacenamiento inadecuado, la contaminación de las plantas por productos químicos, metales pesados o microorganismos, la adulteración durante la producción y la falta o el mal etiquetado de los productos.

\section{¿QUÉ ES LA HEPATOTOXICIDAD O TOXICIDAD HEPÁTICA?}

La hepatotoxicidad o enfermedad hepática tóxica es el daño del hígado producido por la toma de compuestos químicos u orgánicos. El hígado es el principal órgano implicado en el metabolismo de cualquier sustancia ajena al organismo incluidos los productos botánicos, lo cual hace que sea especialmente susceptible a la toxicidad por dichas sustancias. Contrariamente a la creencia popular, lejos de ser seguros, algunos remedios herbales comportan un riesgo de toxicidad hepática en algunos casos con consecuencias fatales.

\section{¿ES MUY FRECUENTE?}

Estas reacciones son poco frecuentes e imprevistas, dado que ocurren únicamente en un número muy reducido de sujetos expuestos, probablemente debido a variaciones genéticamente condicionadas e influenciados por circunstancias ambientales concretas o situaciones de enfermedad concomitante.

\section{¿QUÉ SÍNTOMAS OCASIONA?}

La mayoría de las reacciones hepatotóxicas cursan de forma asintomática o con síntomas inespecíficos, por lo que se descubren habitualmente mediante la aparición de un aumento de los niveles de las enzimas hepáticas (transaminasas y/o de las enzimas de colestasis) en el análisis sanguíneo. Los síntomas más frecuentes cuando aparecen son el cansancio, la pérdida de apetito, el malestar general, molestias abdominales de predominio en el cuadrante superior derecho y la ictericia (coloración amarillenta de la piel y de las mucosas).

\section{¿CÓMO SE DIAGNOSTICA?}

El diagnóstico de enfermedad hepática se realiza mediante la historia clínica y los resultados de los análisis. El diagnóstico de hepatotoxicidad, es decir, llegar a la conclusión de que dicha enfermedad hepática ha sido producida por medicamentos o sustancias de herboristería es más complicado ya que no existen pruebas para su confirmación y, por lo tanto, el estudio se centra fundamentalmente en la exclusión de otras posibles causas de dicha enfermedad (virus de hepatitis, el alcohol, enfermedades metabólicas, alteraciones biliares o tumorales) mediante la realización de análisis sanguíneos y pruebas de imagen (ecografía). Además es importante realizar una exhaustiva historia clínica y farmacológica para identificar una relación temporal adecuada entre la toma de dichas sustancias y el inicio de la enfermedad. Por último, en algunas ocasiones en las que no es posible excluir otras causas o existen dudas diagnósticas puede ser necesario recurrir a la realización de una biopsia del hígado.

\section{¿CUÁL ES SU PRONÓSTICO?}

Los compuestos "naturales" han sido relacionados con distintos cuadros de enfermedad hepática que pueden variar entre alteraciones leves de los análisis que no provocan síntomas y no dejan secuelas, hasta lesiones graves que pueden llegar a precisar un trasplante de hígado o que pueden conducir incluso al fallecimiento del paciente, lo cual afortunadamente ocurre en raras ocasiones.

\section{¿QUÉ PRODUCTOS NATURALES HAN SIDO RELACIONADOS CON EPISODIOS DE TOXICIDAD HEPÁTICA?}

El gobierno español junto con la agencia española de farmacovigilancia publicaron una lista de plantas cuya venta al público fuera de los establecimientos sanitarios y al margen de la legislación sobre medicamentos quedaba prohibida o restringida debido a la toxicidad demostrada (OM 190/2004, BOE 32 de febrero de 2004). Por desgracia, el escaso control sobre los preparados que se venden en herbolarios y tiendas de dietética no permite descartar que se sigan vendiendo algunos de estos compuestos. En este listado, los productos que han sido relacionados con episodios de hepatotoxicidad son los siguientes: extracto etanólico de Camelia Sinensis (Exoli$\mathrm{se}^{\circledR}$, té verde), Actracilys gummifera, celandina mayor, crotalaria, Ephedra (Ma Huang), heliotropium, Piper methysticum rizoma (kava-kava), Rhamnus purshiana (cáscara sagrada), Senecio vulgaris, Teucrium chamaedrys (camedrio, germander), Symphytum officinale (consuelda) y el viscus album.

Otros productos que han sido relacionados con lesiones hepáticas son la crotalaria, hierbas chinas como el Lycopodium serratium (Jin Bu Huan) o Dai-Saiko-To, Larrea tridentata (Chaparral), Cassia angustifolia (senna), Callilepsis laureola, Morinda citrifollia (Zumo de noni), Viscus album (muérdago, mistletoe), Scutellaria (Skullcap), Valeriana officinalis, Hedeoma pulegioides, Menta pulegium (Pennyroyal oil, poleo), Couterea latifloral (Copalchi), Chitosan, Cinnamomum camphora (aceite de alcanfor, Vicks VapoRub), Aesculus Hippocastanum, cimicifuga racemosa (black cohosh), Serenoa Repens (Saw Palmetto o Palma enana americana), ácido úsnico, Azadirachta indica (nim, margosa o lila india), Aloe vera, Glycine $\max$ (isoflavonas de soja) y productos utilizados en la medicina ayurveda en la India (pueden contener tanto plantas como Centella asiática, como metales). Por último, han sido descritos numerosos casos de toxicidad hepática por productos combinados como Herbalife o Hidroxycut.

\section{¿QUÉ TRATAMIENTO TIENE?}

Salvo raras excepciones, no existe una terapia específica para el tratamiento de la enfermedad hepática tóxica. Por lo tanto, el principal tratamiento de un cuadro de hepatotoxicidad es la retirada inmediata del producto sospechoso o culpable de producir dicha lesión y las medidas sintomáticas y de soporte.

Miren García Cortés y Alejandra Fernández Castañer

Unidad de Gestión Clínica de Aparato Digestivo. Hospital Universitario Virgen de la Victoria de Málaga. Centro de Investigación Biomédica en Red de Enfermedades Hepáticas y Digestivas (CIBERehd). Málaga

Aunque se ha puesto el máximo cuidado en la elaboración de estos textos, los autores, coordinadores y la propia Revista Española de Enfermedades Digestivas, recuerdan que no sustituyen a la opinión y consejo de un médico y que no se hacen responsables de las decisiones tomadas basándose en los mismos. 